\title{
Faktor Penghambat Implementasi Sistem Informasi Manajemen Rumah Sakit di RSUD Blambangan Banyuwangi
}

\section{Inhibiting Factors in Hospital Information System Implementation at Blambangan General Hospital Banyuwangi}

\author{
Suyanto ${ }^{1}$, Hidayat Taufiq ${ }^{2}$, Indiati ${ }^{3}$ \\ ${ }^{1}$ Program Studi Magister Manajemen Rumah Sakit Fakultas Kedokteran Universitas Brawijaya Malang \\ ${ }^{2}$ Rumah Sakit Umum Daerah Blambangan Banyuwangi \\ ${ }^{3}$ Rumah Sakit Al Huda Banyuwangi
}

\begin{abstract}
ABSTRAK
Penerapan Sistem Informasi Rumah Sakit (SIM RS) berbasis komputer semakin menjadi tuntutan, namun implementasinya memerlukan upaya lebih dari sekedar pengembangan SIM RS. Penelitian ini bertujuan untuk mengetahui faktor penghambat pelaksanaan SIM RS di Rumah Sakit Umum Daerah Blambangan Kabupaten Banyuwangi yang telah mengembangkan SIM RS. Penelitian ini merupakan penelitian deskriptif kualitatif dengan wawancara dan observasi sebagai petode pengambilan data pada periode September hingga Oktober 2014. Analisis akar masalah menggunakan fishbone melalui brainstorming, kemudian disepakati akar masalah yang paling penting dan dipilih alternatif solusi yang paling efektif, relatif murah, mudah dan bisa dikerjakan dalam waktu. Hasil penelitian mengidentifikasi tiga akar masalah utama kelengkapan standar prosedur operasional (SPO), kejelasan tugas pokok dan fungsi, serta supervise yang belum efektif sebagai penyebab belum optimalnya SIMRS secara maksimal. Sebagai langkah awal RS telah mengembangkan 12 SPO melalui proses pengkajian dan uji coba yang akan ditindaklanjuti dengan evaluasi implementasi berkelanjutan.
\end{abstract}

Kata Kunci: Faktor penghambat, implementasi, SIM RS, standar prosedur operasional

\section{ABSTRACT}

Implementation of computer-based Hospital Information System (SIM RS) is now on demand, but its implementation requires more effort than just the development of SIM RS. This study aims to determine the factors inhibiting the implementation of SIM RS at Blambangan General Hospital Banyuwangi which has developed SIM RS. This research is descriptive qualitative with interviews and observations as data collection methods in a period of September to October 2014. Fishbone analysis was used to identify the root of the problem through brainstorming to select the most important root of the problem and choose alternative solutions that are effective, relatively inexpensive, easy, and can be done in time. The results identify three major problems, namely completeness of standard operating procedures (SOP), transparency of the main tasks and functions, and ineffective supervision as the causes of not optimal SIM RS. As a first step, the hospital has developed 12 SOPs through assessment and trial processes which will be followed by evaluation on ongoing implementation.

Keywords: Computer-based hospital information system, inhibiting factors, implementation, SOP

Jurnal Kedokteran Brawijaya, Vol. 28, Suplemen No. 2, 2015; Korespondensi: Suyanto. Program Studi Magister Manajemen Rumah Sakit Fakultas Kedokteran Universitas Brawijaya Malang, Jl. Veteran Malang 65145 Tel. (0341)569117 Email: suyanto18@yahoo.com 


\section{PENDAHULUAN}

Perkembangan ilmu dan teknologi terutama dibidang komunikasi informasi dan komputerisasi telah mengubah wajah dunia dari konvensional menuju dunia modern. Pengaruh kemajuan tersebut tidak dapat dihindari, hal ini berlaku juga di bidang perumahsakitan. Rumah sakit di Indonesia saat ini berlomba-lomba mengembangkan diri dalam hal kualitas manajemen pelayanan kesehatan dengan menerapkan sistem informasi rumah sakit berbasis komputer untuk mendukung perubahan dan perbaikan di semua aspek dan bidang layanan, termasuk sarana, prasarana, finansial, perlengkapan alat-alat medis, logistik serta sumber daya manusia $(1,2)$. Sejak berlakunya Undang-Undang Nomor 14 Tahun 2008 tentang Keterbukaan Informasi Publik (KIP) maka tersedianya data dan informasi mutlak dibutuhkan terutama oleh badan layanan umum seperti rumah sakit. Data dan Informasi tersebut setiap tahunnya mengalami perubahan seiring dengan perkembangan jaman, sehingga revisi dalam Sistem Informasi Rumah Sakit (SIRS) yang sudah ada saat ini mutlak dibutuhkan.

SIRS adalah suatu proses pengumpulan, pengolahan dan penyajian data rumah sakit. Sesuai ketentuan Pasal 52 ayat (1) Undang-Undang Nomor 44 Tahun 2009 tentang rumah sakit, setiap rumah sakit wajib melakukan pencatatan dan pelaporan tentang semua kegiatan penyelenggaraan rumah sakit dalam bentuk Sistem Informasi Manajemen Rumah Sakit (SIMRS). Pasal 3 ayat 1 dari Peraturan Menteri Kesehatan Republik Indonesia No. 82 tahun 2013 tentang Sistem Informasi Manajemen Rumah Sakit (SIMRS) dinyatakan bahwa setiap rumah sakit wajib menyelenggarakan SIMRS (3). Berdasarkan perundangan tersebut Rumah Sakit Umum Daerah (RSUD) Blambangan Kabupaten Banyuwangi memberlakukan SIMRS $(4,5)$. Menurut Peraturan Menteri Kesehatan Republik Indonesia No. 82 tahun 2013 yang dimaksud SIMRS adalah suatu Sistem Teknologi Informasi Komunikasi yang memproses dan mengintegrasikan seluruh alur proses pelayanan rumah sakit dalam bentuk jaringan koordinasi, pelaporan dan prosedur administrasi untuk memperoleh informasi secara tepat dan akurat, dan merupakan bagian dari sistem informasi kesehatan. SIMRS memberikan kemudahan dalam menjalankan manajemen perumahsakitan $(3,5,6)$.

Terdapat lima komponen yang mendasari implementasi SIMRS yaitu sumber daya manusia (SDM), perangkat keras (hardware), perangkat lunak (software), data, jaringan (Local Area Network/LAN) $(5,7)$. SDM sebagai pengguna SIMRS merupakan faktor utama dalam penerimaan sebuah teknologi baru. Proses adopsi dalam penerapan SIMRS merupakan bagian perilaku manusia dan menentukan kelancaran penerapan SIMRS. Perangkat teknologi berperan pada tingkat kesulitan/kemudahan dalam penerapan serta manfaat bagi individu maupun organisasi, sehingga masing-masing komponen dapat menjadi masalah dan menyebabkan gangguan dalam implementasi SIMRS $(2,5,7)$.

Dalam upaya implementasi SIMRS berbasis komputer ini agar bisa berjalan, maka pihak RSUD Blambangan telah melakukan perjanjian kerjasama antara RSUD Blambangan Banyuwangi dengan Perusahaan Perseroan (PERSERO) PT. Telekomunikasi Indonesia, TBK bernomor: 188/378/429.012/2013 tertanggal 18 Pebruari 2013.
Pihak PT. Telekomunikasi Indonesia memberikan layanan inti TELKOM E-HOSPITAL berupa penyediaan dan implementasi aplikasi SIMRS berbasis Cloud, pelatihan dan pemeliharaan sistem (6). SIMRS di RSUD Blambangan adalah suatu program berbasis komputer yang menggunakan Local Area Network (LAN), dengan kegiatannya berupa pengumpulan data, penyajian data, analisa dan informasi data, yang tersimpan di data base dalam bentuk modul-modul. Berdasarkan daftar layanan kerjasama dengan PT TELKOM, terdapat sebelas modul, yakni modul pendaftaran, modul gawat darurat, modul rawat jalan, modul rawat inap, modul kasir, modul rekam medik, modul penunjang, modul inventory farmasi/gudang farmasi, modul mobilisasi dana/keuangan, modul jasa pelayanan/komite medis dan terakhir modul akuntansi (6).

Untuk mendukung kelancaran tugas SIMRS, telah dibentuk tim tata kelola teknologi informasi di RSUD Blambangan Kabupaten Banyuwangi melalui Keputusan Direktur Nomor: 188/116/KEP/429.402/2013 tertanggal 26 April 2013 yang berfungsi mengembangkan SIMRS di RSUD Blambangan Banyuwangi. Keberhasilan yang sudah dicapai pada saat ini adalah terwujudnya SIMRS berbasis komputer meskipun belum sepenuhnya. Rencana kerja yang akan segera direalisasikan adalah wacana kerjasama dengan Dinas Kependudukan dan Catatan Sipil (DISPENDUKCAPIL) dan Dinas Perhubungan Komunikasi dan Informatika (DISHUBKOMINFO) Kabupaten Banyuwangi dalam mempermudah pengambilan data kependudukan, sehingga unit pendaftaran akan semakin mudah dan cepat dalam hal pendataan setiap pasien baru.

Studi pendahuluan mengidentifikasi permasalahan implementasi SIMRS di RSUD Blambangan Banyuwangi diantaranya karyawan sebagai pengguna belum menggunakan aplikasi tersebut dengan alasan antara lain SIMRS belum terintegrasi dengan unit laboratorium dan radiologi. Karyawan di unit kasir belum bisa melaksanakan SIMRS karena waktu input data dari ruang rawat inap dan penunjang belum tepat. Karyawan di unit farmasi mengalami kendala dalam hal perhitungan stock obat dan belum berjalannya resep elektronik serta alasan-alasan lainnya. Penelitian ini bertujuan untuk mengidentifikasi faktor penghambat yang ditemukan pada SDM, hardware, software, data dan local area network (LAN) dalam pelaksanaan SIMRS di RSUD Blambangan Kabupaten Banyuwangi.

\section{METODE}

Studi ini merupakan penelitian deskriptif kualitatif. Metode pengambilan data melalui wawancara dan observasi di RSUD Blambangan Kabupaten Banyuwangi periode September hingga Oktober 2014. Wawancara tentang proses dan kebijakan manajemen dilakukan kepada Direktur, Bagian Tata Usaha, Sub Bagian Program, Evaluasi dan Pelaporan, serta Tim Tata Kelola Teknologi Informasi. Pada Tabel 1 disajikan tentang check list observasi SIMRS berbasis komputertentangSDM, hardware, software, data dan local area network (LAN) dilakukan di Data Center, serta unit-unit yang telah menjalankan SIMRS yaitu pendaftaran, instalasi gawat darurat (IGD), rawat inap, apotek, hemodialisa. Analisis akar masalah menggunakan fishbone melalui brainstorming yang dihadiri oleh 30 peserta,didapatkan 
faktor penghambat pelaksanaan SIMRS di RSUD Blambangan Kabupaten Banyuwangi. Peserta yang hadir termasuk pihak manajemen (Direktur, Bagian Pelayananan, Bidang Penunjang, Bagian Tata Usaha), Tim Tata Kelola Teknologi Informasi serta pengguna SIMRS.

\section{HASIL}

\section{Permasalahan dalam Penerapan SIMRS}

Hasil observasi (Tabel 1) menunjukkan secara keseluruhan terdapat permasalahan di hampir semua aspek, kecuali kecukupan sumber daya manusia. Penerapan SIM RS belum diikuti dengan penataan sistem, pembentukan budaya, kesiapan perangkat, juga kajian kesesuaian sistem. Data pada wawancara dan observasi menjadi dasar dalam FGD untuk menganalisis akar masalah dengan menggunakan check list observasi SIMRS berbasis komputer

Pada dimensi man dari fishbone (Gambar 1) didapatkan
Tim SIMRS di Struktur Organisasi belum berkoordinasi, kurang komitmen petugas ruangan, belum ada kepedulian pemakai, belum ada kedisiplinan entry data, kompetensi user belum seragam, kurangnya pelatihan SIMRS. Dimensi methode didapatkan belum lengkapnya standar prosedur operasional/SPO SIMRS, tugas pokok dan fungsi (TUPOKSI) organisasi SIMRS belum jelas, belum ada supervisi SIMRS dari manajemen, belum semua standar pelayanan minimal/SPM dibuatkan SIM, daftar tarif laboratorium dan radiologi belum jelas, belum ada prosedur pelatihan SIM rutin, belum ada realisasi kerjasama dengan DISPENDUKCAPIL dan DISHUBKOMINFO, aplikasi BPJS belum sempurna terhubung dengan SIMRS, hasil studi SIMRS belum bisa dijalankan. Dimensi environment didapatkan ruang SIMRS kurang representatif, belum terbangunnya budaya kerja. Dimensi material didapatkan hardware kurang di beberapa ruangan, belum lengkap sarana SIM di tiap unit, koneksi sering terganggu. Dimensi machine didapatkan server sering panas, LAN sering macet.

Tabel 1. Check list observasi SIMRS berbasis komputer

\begin{tabular}{|c|c|c|c|c|}
\hline & Aspek yang Diamati & Ada & Tidak & Keterangan \\
\hline \multirow[t]{13}{*}{1} & Sumberdaya manusia & $\checkmark$ & & \\
\hline & Kecukupan jumlah user SIMRS & $\checkmark$ & & $\begin{array}{l}\text { Seluruh tenaga medis dan nonmedis } \\
\text { (cukup) }\end{array}$ \\
\hline & Kecukupan pelatihan SIMRS bagi user & & $\checkmark$ & Belum semua ikut \\
\hline & Komitmen petugas ruangan/ unit & & $\checkmark$ & Tidak ada supervisi \\
\hline & Kepedulian user & & $\checkmark$ & Belum ada budaya \\
\hline & Adanya kedisiplinan entry data & & $\checkmark$ & Belum ada budaya \\
\hline & Adanya keseragaman kompetensi user & & $\checkmark$ & \\
\hline & Adanya koordinasi tim SIMRS & & $\checkmark$ & Tim belum kompak \\
\hline & Adanya manfaat pelatihan SIMRS & & $\checkmark$ & Hasil pelatihan belum diaplikasikan \\
\hline & Adanya budaya kerja & & $\checkmark$ & \\
\hline & Adanya supervisi dari manajemen & & $\checkmark$ & $\begin{array}{l}\text { Manajemen belum membuat jadwal } \\
\text { supervisi }\end{array}$ \\
\hline & $\begin{array}{l}\text { Adanya reward dan punishment dalam } \\
\text { menjalankan SIMRS }\end{array}$ & $\checkmark$ & & Belum ada ketegasan manajemen \\
\hline & Adanya petugas dari tim TELKOM & $\checkmark$ & & $\begin{array}{l}\text { Tetapi hanya sebagai mediator pada } \\
\text { problem yg sifatnya cloud dan tidak } 24 \text { jam }\end{array}$ \\
\hline \multirow[t]{5}{*}{2} & Hardware & & & \\
\hline & Adanya kelengkapan komputer di ruangan & & $\checkmark$ & IGD dan Apotik masih kurang \\
\hline & Adanya kelengkapan sarana di ruangan & & $\checkmark$ & Kurang monitor, $\mathrm{AC}$ \\
\hline & Kecukupan Server & & $\checkmark$ & Hanya 2 yang aktif dan kurang besar \\
\hline & Adanya masalah pada server & $\checkmark$ & & $\begin{array}{l}\text { Beban terlalu berat, sehingga sering panas } \\
\text { dan hang }\end{array}$ \\
\hline \multirow[t]{7}{*}{3} & Kesesuaian ruang SIMRS (data center) & & $\checkmark$ & Terlalu sempit \\
\hline & Software & & & \\
\hline & Adanya kesesuaian aplikasi yang tersedia & & & $\begin{array}{l}\text { Kadang tidak sesuai antara aplikasi yang } \\
\text { ada dengan harapan RS }\end{array}$ \\
\hline & Adanya gangguan sistem koneksi & & & Terkadang terputus \\
\hline & Adanya SPO menjalankan SIMRS & & $\checkmark$ & $\begin{array}{l}\text { Karena tidak punya SPO, sering terjadi } \\
\text { tumpang tindah tanggung jawab }\end{array}$ \\
\hline & Adanya TUPOKSI petugas/ tim & & $\checkmark$ & Penunjukan kerja belum jelas \\
\hline & Adanya masalah aplikasi SIMRS dari Bandung & & $\checkmark$ & $\begin{array}{l}\text { Masih komunikasi jarak jauh dengan Pusat } \\
\text { TELKOM Bandung }\end{array}$ \\
\hline \multirow[t]{7}{*}{4} & Data & & $\checkmark$ & \\
\hline & Adanya daftar tarif laboratorium & & $\checkmark$ & Belum lengkap \\
\hline & Adanya daftar tarif radiologi & & $\checkmark$ & Belum lengkap \\
\hline & Aplikasi BPJS & & $\checkmark$ & Sering bermasalah \\
\hline & Adanya data SPM menjadi SIMRS & & $\checkmark$ & Belum tuntas \\
\hline & Adanya kerjasama dengan DISPENDUKCAPIL & & $\checkmark$ & Belum ada \\
\hline & Adanya kerjasama dengan DISHUBKOMINFO & & $\checkmark$ & Belum ada \\
\hline \multirow[t]{3}{*}{5} & L.A.N & & $\checkmark$ & \\
\hline & Kelancaran jalur & & $\checkmark$ & Sering putus \\
\hline & Adanya kabel-kabel konektor antar ruangan & $\checkmark$ & & Tapi belum lengkap dan belum teratur \\
\hline
\end{tabular}




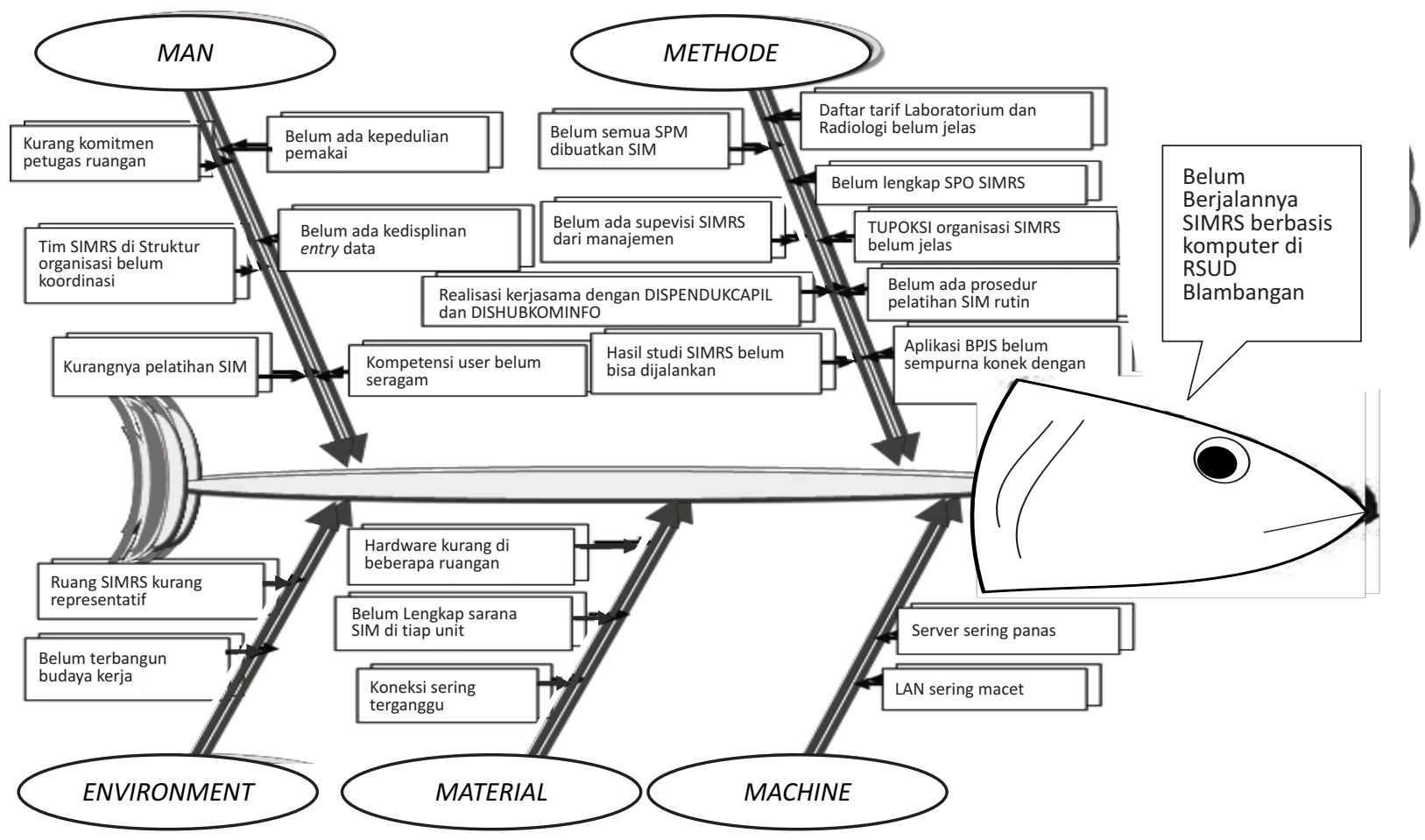

Gambar 1. Diagram fishbone belum berjalannya SIMRS berbasis komputer di RSUD

Berdasarkan analisis fishbone ditemukan beberapa akar masalah yang menjadi penyebab belum berjalannya SIMRS berbasis komputer di RSUD Blambangan Banyuwangi sehingga idealnya diperlukan solusi secara lengkap dari seluruh faktor penghambat dengan perencanaan yang sistematis. Pada Tabel 2 disajikan skoring skala prioritas dari akar masalah dengan metode USGL dan ditemukan 3 akar masalah utama yaitu belum lengkap SPO SIMRS, TUPOKSI organisasi SIMRS belum jelas, belum ada supervisi SIMRS dari manajemen.

Tabel 2. Skoring skala prioritas akar masalah

\begin{tabular}{|c|c|c|c|c|c|c|c|}
\hline \multirow{3}{*}{$\begin{array}{c}\text { No } \\
1\end{array}$} & \multicolumn{7}{|c|}{ SIMRS Belum Berjalan } \\
\hline & Uraian Masalah & \multicolumn{4}{|c|}{ Skoring USGL } & \multirow{2}{*}{$\begin{array}{c}\text { Nilai } \\
500\end{array}$} & \multirow{2}{*}{$\frac{\text { Rank }}{\text { II }}$} \\
\hline & $\begin{array}{l}\text { TUPOKSI organisasi SIMRS } \\
\text { belum jelas }\end{array}$ & 5 & 4 & 5 & 5 & & \\
\hline 2 & Belum lengkap SPO SIMRS & 5 & 5 & 5 & 5 & 625 & $!$ \\
\hline 3 & $\begin{array}{l}\text { Realisasi kerjasama dengan } \\
\text { DISPENDUKCAPIL dan } \\
\text { DISHUBKOMINFO belum ada }\end{array}$ & 3 & 4 & 4 & 3 & 144 & VI \\
\hline 4 & $\begin{array}{l}\text { Aplikasi BPJS belum konek } \\
\text { sempurna dengan SIMRS }\end{array}$ & 1 & 2 & 2 & 1 & 4 & VIII \\
\hline 5 & $\begin{array}{l}\text { Hasil studi SIMRS belum bisa } \\
\text { dijalankan }\end{array}$ & 3 & 2 & 2 & 2 & 24 & VII \\
\hline 6 & $\begin{array}{l}\text { Belum semua SPM telah } \\
\text { dibuatkan SIM }\end{array}$ & 1 & 2 & 2 & 1 & 4 & VIII \\
\hline 7 & $\begin{array}{l}\text { Daftar tarif laboratorium dan } \\
\text { radiologi yang baru belum } \\
\text { masuk SIMRS }\end{array}$ & 1 & 2 & 2 & 1 & 4 & VIII \\
\hline 8 & $\begin{array}{l}\text { Belum ada supervisi SIMRS } \\
\text { dari manajemen }\end{array}$ & 5 & 4 & 4 & 4 & 320 & III \\
\hline 9 & $\begin{array}{l}\text { Belum ada prosedur } \\
\text { pelatihan SIM rutin }\end{array}$ & 4 & 3 & 4 & 4 & 192 & IV \\
\hline 10 & $\begin{array}{l}\text { Belum ada kepedulian } \\
\text { pemakai di unit }\end{array}$ & 3 & 3 & 4 & 5 & 180 & v \\
\hline
\end{tabular}

Tabel 2. Skoring skala prioritas akar masalah (Lanjutan)

\begin{tabular}{llllllllc}
\hline No & \multicolumn{8}{c}{ SIMRS Belum Berjalan } \\
\cline { 2 - 8 } & \multicolumn{1}{c}{ Uraian Masalah } & \multicolumn{1}{c}{ Skoring USGL } & Nilai & Rank \\
\hline 11 & $\begin{array}{l}\text { Belum ada kedisiplinan entry } \\
\text { data }\end{array}$ & 3 & 3 & 4 & 5 & 180 & V \\
12 & 2 & 3 & 2 & 2 & 24 & VII \\
& $\begin{array}{l}\text { Kompetensi user belum } \\
\text { seragam }\end{array}$ & 2 & & & &
\end{tabular}

Pada Tabel 3 disajikan alternatif pemecahan masalah atau solusi dari 3 akar masalah utama dan dilakukan pembobotan dari solusi akar masalah untuk menetapkan prioritas utama alternatif solusi. Prioritas solusi atau pemecahan masalah yang harus dilakukan adalah membuat SPO SIMRS yang belum lengkap, studi banding untuk bahan pembuatan SPO, meminta pihak PT Telkom memediasi membuat SPO, membuat TUPOKSI tim SIMRS, menugaskan tim tata kelola teknologi informasi membentuk tim SIMRS, melakukan supervisi ke setiap ruangan secara rutin, menyusun jadwal supervisi, dan menentukan ketua regu tiap supervisi.

Tabel 3. Alternatif pemecahan masalah

\begin{tabular}{|c|c|c|}
\hline $\begin{array}{l}\text { No/ } \\
\text { Ranking }\end{array}$ & Akar Masalah & Solusi/ Pemecahan Masalah \\
\hline \multirow[t]{3}{*}{1} & Belum lengkap & Membuat SPO SIMRS yang belum lengkap \\
\hline & SPO SIMRS & $\begin{array}{l}\text { Studi banding untuk bahan pembuatan } \\
\text { SPO }\end{array}$ \\
\hline & & $\begin{array}{l}\text { Meminta pihak PT Telkom memediasi } \\
\text { membuat SPO }\end{array}$ \\
\hline \multirow[t]{2}{*}{2} & TUPOKSI & Membuat TUPOKSI tim SIMRS \\
\hline & $\begin{array}{l}\text { organisasi SIMRS } \\
\text { belum jelas }\end{array}$ & $\begin{array}{l}\text { Menugaskan tim tata kelola teknologi } \\
\text { informasi Membentuk tim SIMRS }\end{array}$ \\
\hline
\end{tabular}


Tabel 3. Alternatif pemecahan masalah (Lanjutan)

\begin{tabular}{cll}
$\begin{array}{c}\text { No/ } \\
\text { Ranking }\end{array}$ & Akar Masalah & \multicolumn{1}{c}{ Solusi/ Pemecahan Masalah } \\
\hline 3 & $\begin{array}{l}\text { Belum ada } \\
\text { supervisi SIMRS } \\
\text { dari manajemen }\end{array}$ & $\begin{array}{l}\text { Melakukan supervisi ke setiap ruangan } \\
\text { secara rutin } \\
\end{array}$ \\
& $\begin{array}{l}\text { Menyusun jadwal supervisi } \\
\text { Mentukan ketua regu tiap supervisi }\end{array}$ \\
\hline
\end{tabular}

Pada kegiatan brainstorming tersebut, dilakukan pemilihan alternatif solusi yang paling efektif, relatif murah, mudah dan bisa dikerjakan dalam waktu singkat seperti (Tabel 4). Berdasarkan penilaian di atas, permbuatan SPO SIMRS yang belum lengkap merupakan prioritas pilihan solusinya dan dilakukan program pembuatan SPO SIMRS.

Berdasarkan pilihan solusi dilakukan penyusunan plan of action untuk mengembangkan SPO SIMRS. Tahapan (plan of action) proyek pembuatan SPO SIMRS yang belum lengkap dilakukan selama 4 minggu dengan tahapan sebagai berikut; persiapan, menyusun Tim pembuat SPO SIMRS, mengumpulkan bahan untuk membuat SPO SIMRS, merancang dan menuliskan SPO, sosialisasi, uji coba pelaksanaan, revisi dan perbaikan SPO, pengesahan, implementasi dan pemeliharaan atau audit. Semua tahapan tersebut telah dilakukan dan menghasilkan 12 SPO SIMRS. Keseluruhan SPO yang disusun meliputi: menghidupkan dan mematikan komputer, tindakan ketika terjadi permasalahan dalam menghidupkan, mematikan, dan menjalankan komputer, penggabungan nomer rekam Medik, tata cara mengganti user log in, entry data pada saat peralihan perubahan tanggal, modul pendaftaran, gawat darurat, modul, rawat inap, hemodialisa, rawat jalan, kasir.

\section{DISKUSI}

Pelaksanaan SIMRS berbasis komputer dipengaruhi berbagai faktor, seperti besar kecilnya fasilitas kesehatan, ketersediaan unit teknologi informasi dan tenaga pendukungnya serta kebijakan nasional dan lokal. Penelitian oleh Hariana dkk, tentang penggunaan SIMRS di 48 rumah sakit di Daerah Istimewa Yogyakarta menyimpulkan bahwa peran organisasi dalam menyediakan unit SIM dan sumber daya manusia dengan latar belakang teknologi informasi sangat mendukung terhadap pengembangan dan keberlangsungan SIMRS. Penelitian tersebut masih berfokus pada fungsi administrasi dan belum sepenuhnya pada fungsi klinis (7). Penerapan SIMRS pada pelayanan klinis di Indonesia dibandingkan Negara maju masih terbatas. Survei yang dilakukan oleh Jha et al menemukan bahwa rumah sakit di Amerika Serikat yang telah menggunakan sistem Electronic Health Records (EHC) dasar atau komprehensif pada tahun 2008 sekitar $8,7 \%$ dari seluruh rumah sakit di Amerika Serikat dan pada tahun 2009 sekitar 11,9\% dari seluruh rumah sakit di Amerika Serikat (8).

Pemberlakuan SIMRS baru diundangkan di Indonesia sejak keluarnya Undang-Undang Nomor 44 Tahun 2009 dan Peraturan Menteri Kesehatan Republik Indonesia No. 82 tahun 2013 bahwa setiap rumah sakit wajib melakukan pencatatan dan pelaporan tentang semua kegiatan penyelenggaraan rumah sakit dalam bentuk SIMRS. Pengembangan SIMRS berbasis komputer di RSUD Blambangan Banyuwangi dimulai awal 2013 dengan mengadakan kerjasama dengan PT Telkom Indonesia. Hingga saat studi dilakukan unit yang telah menggunakan SIMRS adalah unit pendaftaran, unit IGD, unit rawat inap, unit apotek, unit hemodialisa, sedangkan unit lainnya belum memberlakukan SIMRS. Hal ini sesuai dengan penelitian Hariana, dkk yang menyarankan penerapan SIM secara bertahap (7)

Penelitian yang dilakukan oleh Rachmi, Susanto dan Herdiyanti menyatakan bahwa agar penggunaan Teknologi Informasi (TI) dapat berfungsi dengan baik, diperlukan prosedur penerapan tata kelola TI untuk mengatur dan mengelola aktivitasnya, salah satu tata kelola $\mathrm{TI}$ yang dimaksud adalah berupa prosedur kerja $(8,9)$. Lee,

Tabel 4. Pemilihan alternatif solusi masalah

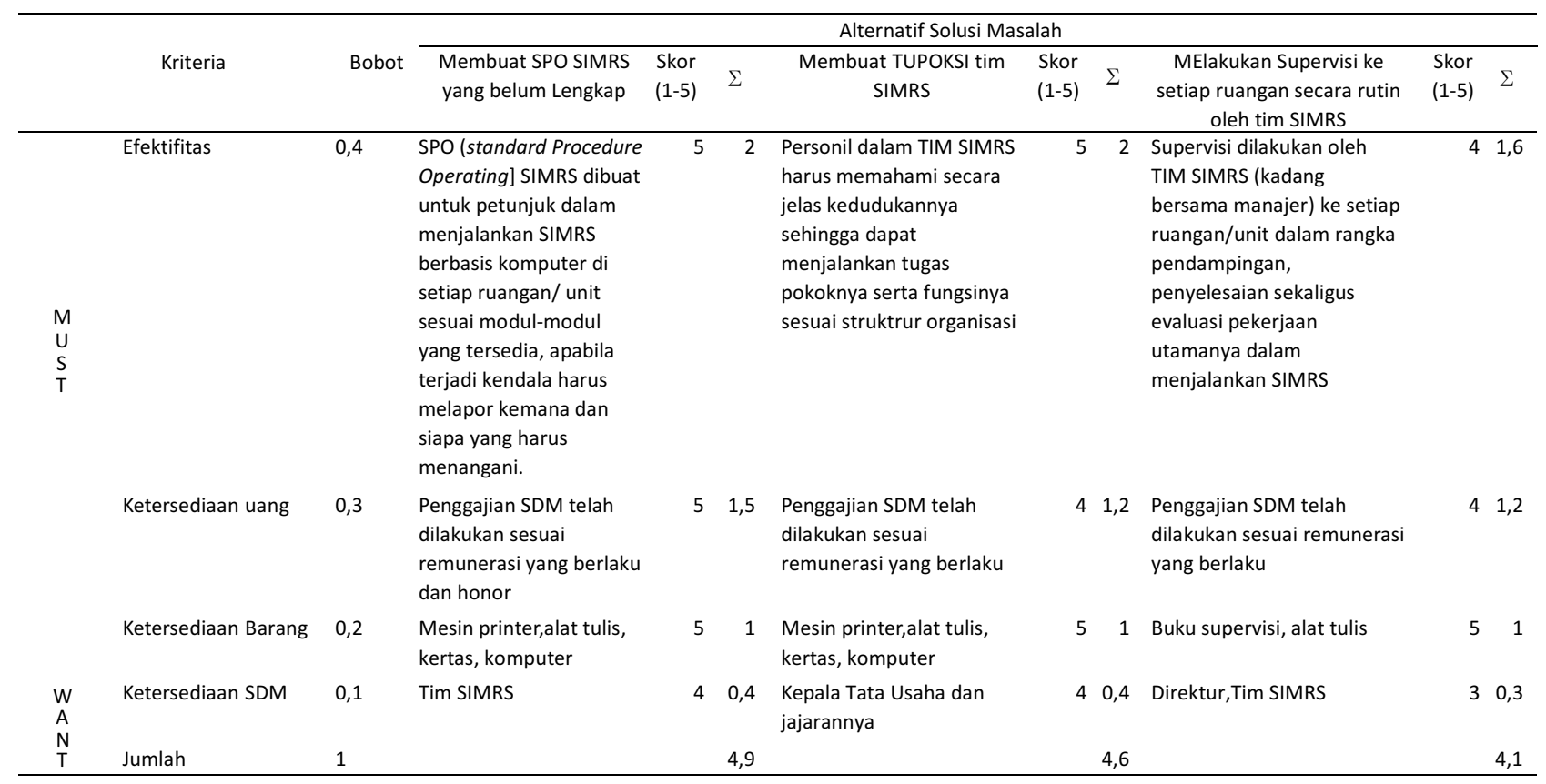


Ramayah dan Zakaria menyimpulkan bahwa ada tiga kategori penghambat adopsi teknologi informasi yaitu tantangan organisasi, tantangan manusia, dan tantangan teknologi (10-14).

Studi ini mengidentifikasi bahwa ketidaklengkapan SPO SIMRS menjadi akar masalah utama belum optimalnya implementasi SIM RS. Faktor belum lengkapnya SPO SIMRS menjadi penting karena SPO menjadi panduan yang terdokumentasi secara formal, jelas, lengkap, dan rinci mengenai proses, tugas, dan peran setiap individu atau kelompok yang dilakukan sehari-hari di dalam suatu organisasi. Dilihat dari fungsinya, SPO berfungsi membentuk sistem kerja dan aliran kerja yang teratur, sistematis, serta dapat dipertanggungjawabkan. Dokumen SPO juga menggambarkan tujuan pekerjaan dilaksanakan sesuai dengan kebijakan dan peraturan yang berlaku dalam sebuah organisasi agar mampu mengatasi tantangan seperti adanya kesulitan dalam penggunaannya (15-19).

\section{DAFTAR PUSTAKA}

1. Rika and Ricky MY. Analisis dan Perancangan Sistem Informasi Laboratorium Rumah Sakit Kanker Dharmais dengan Menggunakan Total Architecture Syntesis. (Online). http://ict.binus.edu/file/research/ paper_revisi_renan.pdf [diakses tanggal 23 Januari 2015].

2. Khairani T, Susilo H, dan Riyadi. Implementasi Sistem Informasi Adiministrasi Rumah Sakit Berbasis Komputer untuk Meningkatkan Kinerja Karyawan (Studi pada Billing Systems RSUD Dr.Saiful Anwar Malang). Jurnal Administrasi Bisnis. 2013; 6(2): 1-9.

3. Menteri Kesehatan Republik Indonesia. Permenkes No: 82 Tahun 2013 tentang Sistem Informasi Manajemen Rumah Sakit2013. Jakarta: Kemenkes RI: 2013.

4. PresidenRepublik Indonesia. Undang-undang Republik Indonesia no. 44 tahun 2009 tentang Rumah Sakit. Jakarta: Sekretariat Negara RI: 2009.

5. Kertahadi, Rahman A, Harijanto, dan Wiryawan TR. Modul Kuliah Sistem Informasi Manajemen. Malang: Program Studi MMRS FKUB; 2011.

6. RSUD Blambangan Banyuwangi dan PT Telekomunikasi Indonesia. Perjanjian Kerja Sama antara Rumah Sakit Umum Daerah Blambangan Banyuwangi dengan Perusahan Perseroan (PERSERO) PT. Telekomunikasi Indonesia, TBK Tentang Implementasi Layanan Telkom E-Hospital. Banyuwangi: RSUD Blambangan; 2013.

7. Hariana E, Sanjaya GY, Rahmanti AR, Murtiningsih B, dan Nugroho E. Penggunaan Sistem Informasi Manajemen Rumah Sakit (SIMRS) di DIY. Seminar Nasional Sistem Informasi Indonesia. 2 - 4 Desember 2013.

8. Jha AK, DesRoches CM, Kralovec PD, and Joshi MS. Progress Report On Electronic Health Records In U.S. Hospitals. Health Affairs. 2010; 29(10): 1951-1957.

9. Rachmi A, Susanto TD, danHerdiyanti A. Pembuatan Standard Operating Procedure (SOP) Service Desk
Dalam proses penelitian ini telah disusun SPO SIMRS sesuai dengan identifikasi kebutuhan. Pembuatan SPO SIMRS didasarkan pada kebutuhan dan tuntutan adanya pengendalian mutu terhadap proses kegiatan organisasi yang berisi seperangkat instruksi sebagai petunjuk kerja dalam sistem manajemen. Proses pembuatannya diperlukan tahapan persiapan hingga akhirnya dimplementasikan/diterapkannya SPO SIMRS didalam setiap kegiatan manajemen rumah sakit dan penerapan SIMRS berbasis komputer di seluruh unit layanan rumah sakit dengan mudah, cepat dan tepat $(8,12,14)$. Penerapan SPO SIMRS yang telah dihasilkan memerlukan evaluasi terus menerus serta pemeliharaan bahkan revisi perbaikan berdasarkan hasil kajian evaluasi $(2,9,10)$. Pembuatan SPO SIMRS merupakan awalan solusi dari permasalahan dalam hambatan pelaksanaan SIMRS berbasis komputer di RSUD Blambangan. Perlu dilakukan penelitian lebih lanjut dan mendalam mengenai faktor yang mempengaruhi penerimaan SIMRS berbasis komputer di RSUD Blambangan.

Berdasarkan Kerangka Kerja Itil V3 dengan Menggunakan Metode Analisis Gap Layanan (Studi Kasus: PT. XYZ, Tangerang). Jurnal Teknik Pomits. 2014; 3(2): 175-180.

10. Lee HW, Ramayah T, and Zakaria N. External Factors in Hospital Information System (HIS) Adoption Model: A Case on Malaysia. Journal of Medical Systems. 2012; 36(4): 2129-2140.

11. Saleh AR. Standard Operating Procedure di Perpustakaan Perguruan Tinggi. Forum Perpustakaan Perguruan Tinggi Indonesia Wilayah Jawa Barat, di Universitas Islam Bandung tanggal 29 Desember 2010 Forum Perpustakaan Perguruan Tinggi Indonesia (FPPTI) Wilayah Jawa Barat Bekerja Sama Dengan UPT Perpustakaan UNISBA. 2010.

12. Setiabudi D. Bridging System Jadikan Pelayanan BPJS Kesehatan Lebih Cepat dan Efisien. (Online). http://health.dekiben.com/2014/05/bridgingsystem-solusi-antrian-panjang.html

13. Handayani R. Analisis Faktor-faktor yang Mempengaruhi Minat Pemanfaatan Sistem Informasi dan Penggunaan Sistem Informasi (Studi Empiris pada Perusahaan Manufaktur di Bursa Efek Jakarta). Jurnal Akuntansi dan Keuangan. 2007; 9(2): 76-88.

14. Davis FD. User Acceptance of Information Technology: System Characteristics, User Perceptions and Behavioral Impacts. International Journal of ManMachine Studies. 1993; 38(3); 475-487.

15. Syaukani M, Kusumadewi S, dan Kariyam. Analisis Faktor-faktor yang Mempengaruhi Minat Pemanfaatan dan Perilaku Penggunaan Sistem Ekokardiografi. Jurnal Teknologi. 2013; 6(2); 170-179.

16. Venkatesh V, Morris MG, Davis GB, and Davis FD. User Acceptance of Information Technology: Toward a Unified View 1. MIS Quarterly. 2003; 27(3); 425-478.

17. ShanabEA, Pearson JM, and Setterstrom AJ. Internet Banking and Customers' Acceptance in Jordan: The Unified Model's Perspective. Communications of the Association for Information Systems. 2010; 26(1): 23. 
18. Dasgupda S, Haddad M, Weiss P, and Bermudez E. User Acceptance of Case Tools in System Analysis and Design: An Empirical Study. Journal of Informatics Education Research. 2007; 9(1); 51-78.
19. Bendi RKJ dan Andayani S. Analisis Perilaku Penggunaan Sistem Informasi Menggunakan Model UTAUT. Seminar Nasional Teknologi Informasi \& Komunikasi Terapan 2013 (Semantik 2013). Semarang, 16 November 2013: hal. 277-282. 